\title{
Inhibition of long non-coding RNA NEAT1 impairs myeloid differentiation in acute promyelocytic leukemia cells
}

Chengwu Zeng ${ }^{1,2}$, Yan $X u^{1,2}$, Ling $X u^{1,2}$, Xibao Yu ${ }^{1,2}$, Jingjing Cheng ${ }^{1,2}$, Lijian Yang ${ }^{1}$, Shaohua Chen ${ }^{1}$ and Yangqiu $\mathrm{Li}^{1,2^{*}}$

\begin{abstract}
Background: Acute promyelocytic leukemia (APL) is characterized by the reciprocal translocation $\mathrm{t}(15 ; 17)$, which fuses PML with retinoic acid receptor alpha (RARa). Although PML-RARa is crucially important for pathogenesis and responsiveness to treatment, the molecular and cellular mechanisms by which PML-RARa exerts its oncogenic potential have not been fully elucidated. Recent reports have suggested that long non-coding RNAs (IncRNAs) contribute to the precise control of gene expression and are involved in human diseases. Little is known about the role of IncRNA in APL.

Methods: We analyzed NEAT1 expression in APL samples and cell lines by real-time quantitative reverse transcription-PCR (qRT-PCR). The expression of PML-RARa was measured by Western blot. Cell differentiation was assessed by measuring the surface CD11b antigen expression by flow cytometry analysis.

Results: We found that nuclear enriched abundant transcript 1 (NEAT1), a IncRNA essential for the formation of nuclear body paraspeckles, is significantly repressed in de novo APL samples compared with those of healthy donors. We further provide evidence that NEAT1 expression was repressed by PML-RARa. Furthermore, significant NEAT1 upregulation was observed during all-trans retinoic acid (ATRA)-induced NB4 cell differentiation. Finally, we demonstrate the importance of NEAT1 in myeloid differentiation. We show that reduction of NEAT1 by small interfering RNA (siRNA) blocks ATRA-induced differentiation.
\end{abstract}

Conclusions: Our results indicate that reduced expression of the nuclear long noncoding RNA NEAT1 may play a role in the myeloid differentiation of APL cells.

\section{Background}

Acute promyelocytic leukemia (APL) is characterized by an aberrant chromosomal translocation that fuses a portion of the promyelocytic leukemia $(P M L)$ gene with the retinoic acid receptor $\alpha(R A R \alpha)$ gene [1], and subsequent expression of the PML-RAR $\alpha$ oncoprotein causes a block at the promyelocytic differentiation stage. All-trans retinoic acid (ATRA) has been successfully used as a leukemia therapy to target the transcriptional repression mediated by the PML-RAR $\alpha$ fusion protein. The treatment of the $t(15 ; 17)$ APL with ATRA induces the differentiation of

\footnotetext{
* Correspondence: yangqiuli@hotmail.com

'Institute of Hematology, Medical College, Jinan University, Guangzhou 510632, China

${ }^{2}$ Key Laboratory for Regenerative Medicine of Ministry of Education, Jinan University, Guangzhou 510632, China
}

\section{Biomed Central}

$t(15 ; 17)$ blasts and causes disease regression $[2,3]$ presumably through degradation of the chimeric protein encoded by the PML-RAR $\alpha$ oncogene [4-6].

Although PML-RAR $\alpha$ is crucially important for pathogenesis and responsiveness to treatment, the mechanism by which PML-RAR $\alpha$ exerts its oncogenic potential remains unclear. Previous studies have proposed that PMLRAR $\alpha$ acts as a strong transcriptional repressor for target genes by directly binding their promoter regions, which are thought to include genes indispensable for myeloid differentiation and apoptosis $[7,8]$. However, the number of identified PML-RAR $\alpha$ target genes is limited [7]. Given the structural and functional complexity of PML-RAR $\alpha$, indirect effects of PML-RAR $\alpha$ may play a significant role

(c) 2014 Zeng et al.; licensee BioMed Central Ltd. This is an Open Access article distributed under the terms of the Creative Commons Attribution License (http://creativecommons.org/licenses/by/4.0), which permits unrestricted use, distribution, and reproduction in any medium, provided the original work is properly credited. The Creative Commons Public Domain Dedication waiver (http://creativecommons.org/publicdomain/zero/1.0/) applies to the data made available in this article, unless otherwise stated. 
in leukemic transformation. Indeed, PML-RAR $\alpha$ may even activate the expression a subset of genes $[9,10]$. These data point to the necessity for addressing the issue of indirect PML-RAR $\alpha$-mediated gene expression control.

Mammalian transcriptome studies have revealed large numbers of long transcripts that have no protein-coding potential. We previously demonstrated that microRNAs play a significant role in the regulation of differentiation, proliferation and apoptosis [11,12]. Compared with the research progress of microRNAs, there are thousands of longer transcripts whose functions are unknown. Recently, several long non-coding RNAs (lncRNAs) have been implicated in many types of cancers $[13,14]$. Our preliminary data showed that NEAT 1 is highly expressed in the APL cell line NB4. NEAT1 (nuclear paraspeckle assembly transcript 1) is a nuclear-restricted long noncoding RNA that has two isoforms: 3.7 kb NEAT1_1 and 23 kb NEAT1_2 [15,16]. This non-coding RNA was recently revealed to be an architectural component of a subnuclear structure called the paraspeckle, which is suggested to be involved in regulating gene expression by retaining mRNAs for editing in the nucleus [16,17]. Although considerable progress has been made into the paraspeckle composition, formation, and molecular organization, the biological function of paraspeckles and the role of the NEAT1 lncRNAs are incompletely defined. In addition, it is not yet clear whether lncRNAs are involved in APL pathogenesis. In this study, we aimed to characterize the role and regulation of NEAT1 in APL.

\section{Methods}

\section{Patients and samples}

A total of 43 peripheral blood samples including 31 APL samples at diagnosis and 12 normal donors with informed consent. All of the procedures were conducted according to the guidelines of the Medical Ethics Committees of the Health Bureau of the Guangdong Province of China, and ethical approval was obtained from the Ethics Committee of Medical School of Jinan University for this study.

\section{Cell lines and cell cultures}

NB4, NB4-R2 and U937-PR9 cell lines were kindly provided by Dr. Yueqin Chen (Sun Yat-sen University, Guangzhou, China) and cultured in RPMI 1640 containing 10\% fetal bovine serum. U937-PR9 contains a zinc-inducible PMLRAR $\alpha$ constructed from U937 [18]. The cells were cultured in a humidified atmosphere containing $5 \% \mathrm{CO}_{2}$ at $37^{\circ} \mathrm{C}$. ATRA was purchased from Sigma-Aldrich and used at the following final concentrations: $1 \mu \mathrm{M}$ ATRA (stock $10 \mathrm{mM}$ in EtOH).Cell differentiation was assessed by measuring the surface ITGAM/CD11b antigen expression by flow cytometry analysis.

\section{Quantitative real-time PCR analysis}

qRT-PCR was performed to detect mature lncRNAs and mRNA expression. Briefly, RNA was reverse-transcribed to cDNA using High-Capacity cDNA Reverse Transcription Kits(Applied Biosystems). ATCB served as internal control. Primers were as follows: NEAT1 forward, $5^{\prime}$-CTTCC TCCCTTTAACTTATCCATTCAC-3'; NEAT1 reverse, $5^{\prime}$ CTCTTCCTCCACCATTACCAACAATAC-3'; NEAT1_2 forward, 5' - CAGTTAGT TTATCAGTTCTCCCATCCA3'; NEAT1_2 reverse, 5'-GTTGTTGTCGTCACCTTT CAACTCT -3'. qRT-PCR cycling program: $95^{\circ} \mathrm{C}$ for $15 \mathrm{~min}$, followed by 40 cycles at $95^{\circ} \mathrm{C}$ for $10 \mathrm{~s}$ and $60^{\circ} \mathrm{C}$ for $30 \mathrm{~s}$.

\section{Transfection}

NB4 cells were transfected using the Neon ${ }^{\circledR}$ Transfection System (Invitrogen) with 100 pmol of oligonucleotides in $10 \mu \mathrm{l}$ reactions. Transfection was performed as described previously [19]. The sequences of small interfering RNA (siRNA) that specifically targets the breakpoint region of PML-RAR $\alpha$ were designed as previously described [20]. The following siRNA sequences targeting the NEAT1 are as follows: 5'-GUGAGAAGUUGCUUA GAAACUUUCC-3'.

\section{Western blot}

Cells (NB4 and U937-PR9) were washed twice in phosphate-buffered saline (PBS) and lysed on ice for $30 \mathrm{~min}$ in RIPA buffer. Protein extracts were separated in a sodium dodecyl sulfate polyacrylamide electrophoresis (SDS-PAGE) gel. The proteins were then transferred to a polyvinylidenedifluoride (PVDF) membrane and probed with anti-RAR $\alpha$ (C-20; Santa Cruz Biotechnology) and anti- $\beta$-actin (Sigma-Aldrich) antibodies.

\section{Statistical analysis}

Data were expressed as the mean \pm SD of 3 independent experiments. The significance of the differences between groups was determined by a two-tailed Student $t$ test. A $\mathrm{P}$-value $<0.05$ was considered significant.

\section{Results}

\section{NEAT1 express levels were downregulated in APL}

Because NEAT1 has been proposed to control several biological processes, including the stress response [21] and cellular differentiation [15], we therefore initially examined the expression level of NEAT1 in peripheral blood mononuclear cells (PBMCs) from 31 cases with de novo APL (13 males and 18 females with a median age of 28.5 years and a range of 17-52 years) expressing the $P M L-R A R \alpha$ fusion gene, which is characterized by leukemia blasts blocked at the promyelocyte stage of differentiation. NEAT1 lncRNA is comprised of two isoforms, NEAT1_1 (3.7 kb in humans) and NEAT1_2 
(23 kb in humans ) (Figure 1A), and we used two primer pairs that were designed as previously described to quantify NEAT1 RNA isoforms by real-time quantitative reverse transcription-PCR (qRT-PCR) [22]. One primer set recognizes both NEAT1_1 and NEAT1_2 (total NEAT1), while the other recognizes only NEAT1_2. qRT-PCR revealed that both NEAT1 and NEAT1_2 were significantly decreased in APL patient samples compared with normal granulocytes (Figure 1B), but not the Malat1 lncRNA (Additional file 1: Figure S1A). This result suggested that NEAT1 may be involved in APL pathogenesis.

\section{NEAT1 is suppressed by PML-RARa, and ATRA restores NEAT1 expression}

The PML-RAR $\alpha$ fusion protein is known to be the initiating factor for APL development by transcriptionally repressing retinoic acid and non-retinoic acid target genes, we wondered whether NEAT1 downregulation was a consequence of PML-RAR $\alpha$ expression; thus, we investigated the relationship between NEAT1 and PML-RAR $\alpha$. To examine whether the expression of the NEAT1 lncRNAs is changed by PML-RAR $\alpha$ expression, we used a U937-derived cell line, U937-PR9, which contains a zinc-inducible PML-RAR $\alpha$. U937-PR9 cells were treated with $100 \mu \mathrm{M} \mathrm{ZnSO}$ for the indicated time, and PML-RAR $\alpha$ was significantly upregulated (Additional file 2: Figure S2A). Using this system, we found that NEAT1 expression was significantly reduced in PMLRAR $\alpha$-expressing cells (Figure 2A), but not in parental U937 cells (Additional file 2: Figure S2B), indicating that NEAT1 downregulation may be a consequence of PMLRAR $\alpha$ accumulation. Next, we used a small interfering RNA (siRNA), which was designed according to a previous report in which PML-RAR $\alpha$ was effectively knocked down by specifically targeting its breakpoint region [20]. The knockdown of PML-RAR $\alpha$ by transfection with
si-PML-RAR $\alpha$ was confirmed by $\mathrm{qRT}-\mathrm{PCR}$ and western blot (Additional file 2: Figure S2C). As expected, we found that the expression of NEAT1 was increased by PMLRAR $\alpha$ knockdown (Figure 2B).

Because APL treatment leads to the clearance of leukemia cells and loss of PML-RAR $\alpha$ transcripts, we next investigated the expression of NEAT1 and PML-RAR $\alpha$ in NB4 cells before and after ATRA treatment $(1 \mu \mathrm{M}$, stock: $10 \mathrm{mM}$ in EtOH) to further establish the relationship between NEAT1 and PML-RAR $\alpha$. Using qRT-PCR, the expression level of total NEAT1 and NEAT1_2 in NB4 cells were rapidly increased upon treatment with ATRA. Importantly, NEAT1 expression was not significantly changed in ATRA-resistant NB4-R2 cells upon ATRA treatment, excluding the possibility that the NEAT1 induction observed in NB4 cells represents a nonspecific stress response to ATRA treatment rather than being functional in differentiation (Figure 2C).

\section{NEAT1 inhibition attenuates the myeloid differentiation of APL cells}

The above data show that the PML-RAR $\alpha$ oncoprotein represses the expression of NEAT1, and ATRA treatment reverts the transcriptional repression mediated by the PML-RAR $\alpha$ fusion protein and increases NEAT1, suggesting that NEAT1 may be involved in cell differentiation and leukemogenesis. We then explored the functional role of NEAT1 in the ATRA-induced myeloid differentiation of APL cells. NEAT1 has been previously shown to be effectively knocked down by siRNA [17,23], and it efficiently attenuated the NEAT1 RNA level in this system compared with control siRNA (Figure 3A). Transduced cells were treated with ATRA, and after $48 \mathrm{~h}$, the expression level of CEBPB mRNA and a membrane antigen (ITGAM/ CD11b) associated with granulocytic cell differentiation was measured [24]. We found significantly reduced CEBPB mRNA and ITGAM/CD11b levels in NB4 cells

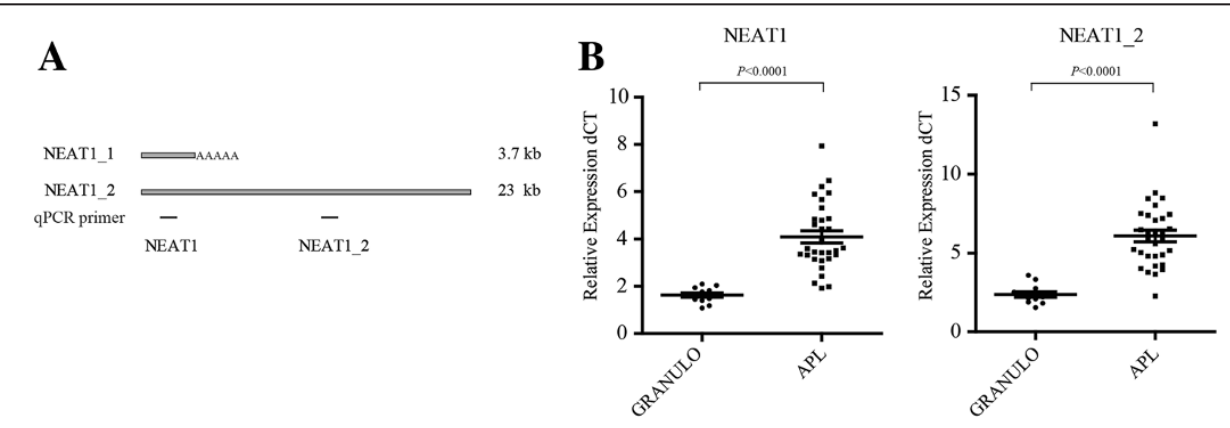

Figure 1 The IncRNA NEAT1 is significantly down-regulated in APL primary patient samples. (A) The NEAT1 isoforms are shown schematically. The black boxes indicate the position of sequences amplified by qRT-PCR. (B) Comparison of NEAT1 expression in granulocytes from healthy donors (Granulo, $n=12$ ) compared with primary APL cells $(n=31)$. The expression levels of the NEAT1 isoforms were evaluated by qRT-PCR. Malat1 IncRNA served as negative control and shown in Additional file 1: Figure S1A. Measured cycle threshold (Ct) values represent log2 expression values. The values were normalized to the expression level of the housekeeping gene ACTB. Each data point represents 1 patient sample. 
A

\section{NEAT1}

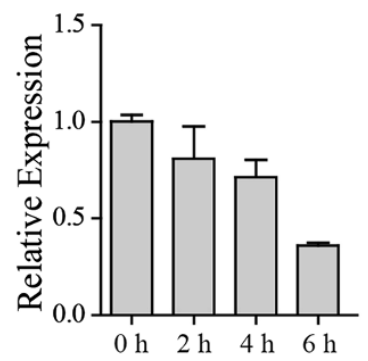

B

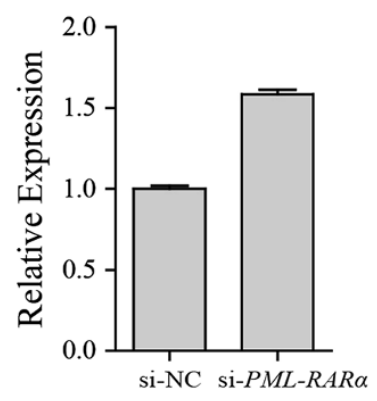

C

NEAT1
NEAT1_2

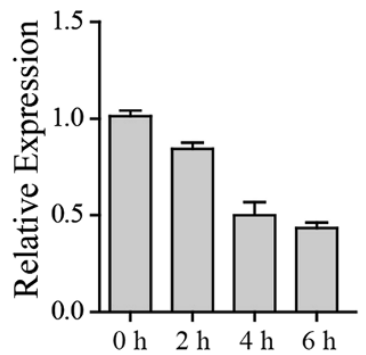

NEAT1_2

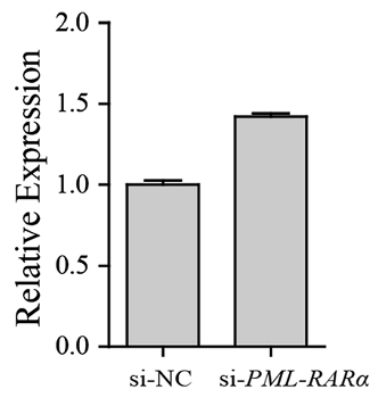

NEAT1_2
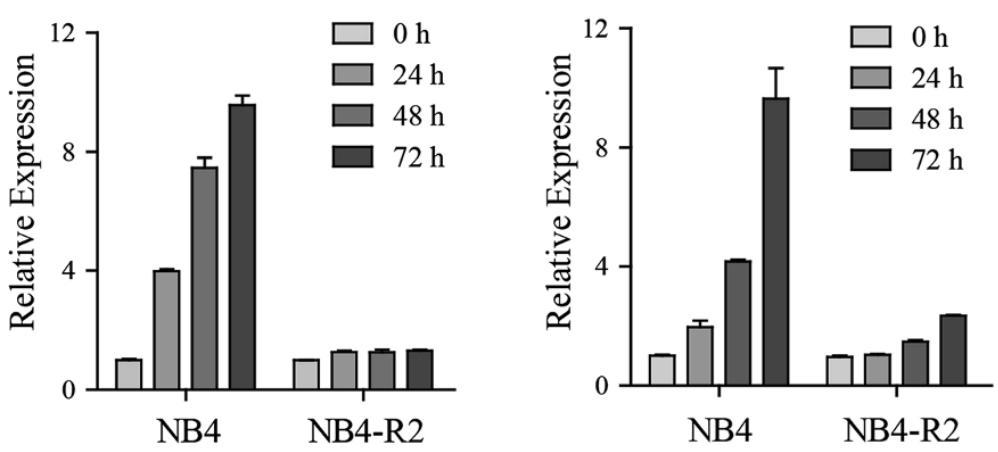

Figure 2 IncRNA NEAT1 is repressed in cells expressing PML-RARa and upregulated in response to ATRA. (A) qRT-PCR analysis of NEAT1 in U937-PR9 cells treated with $100 \mu \mathrm{M} \mathrm{ZnSO}_{4}$ at the indicated time points. A time series of induction for the PML-RARa protein by $\mathrm{ZnSO}_{4}$ is shown in Additional file 2: Figure S2A. (B) qRT-PCR analysis of NEAT1 after knocking down PML-RARa. (C) NB4 and NB4-R2 cells were treated with $1 \mu \mathrm{M}$ ATRA. NEAT1 was measured by qRT-PCR and normalized to the housekeeping gene ACTB. The panels show the mean \pm SD of a representative experiment performed in triplicate.

transfected with si-NEAT1 compared with control cells upon ATRA treatment (Figure 3B and C). These data reveal a novel function for NEAT1 in myeloid differentiation.

\section{Discussion}

In this study, we show that NEAT1 expression is repressed by PML-RAR $\alpha$. In addition, we provide evidence that NEAT1 expression is involved in the differentiation of APL cells.

PML-RAR $\alpha$ is a potent transcriptional repressor in APL cells, and it blocks promyelocyte differentiation. An interesting characteristic of this oncogenic protein is that its transcriptional repression effects can be reverted with pharmacologic doses of ATRA, resulting in the reactivation of genes essential for definitive myeloid differentiation $[2,3,25]$. Recently, lncRNAs have been shown to be dysregulated in various cancers, and several lncRNAs have been functionally linked to cancer and cell differentiation $[13,15]$. In this study, our findings of particular low NEAT1 levels in APL cells indicate that NEAT1 transcription is further repressed by PML-RAR $\alpha$.Indeed, we found that NEAT1 was repressed by PML-RAR $\alpha$, and this repression could be relieved by ATRA. These results suggest that NEAT1 expression is regulated by 


\section{A}

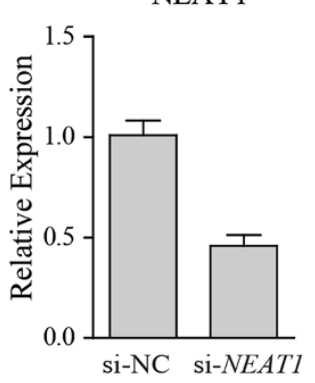

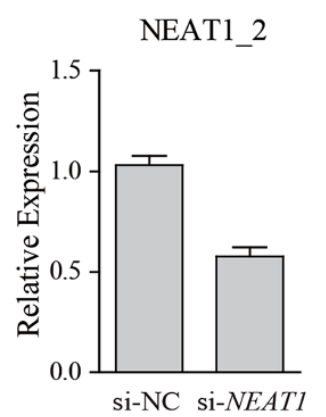

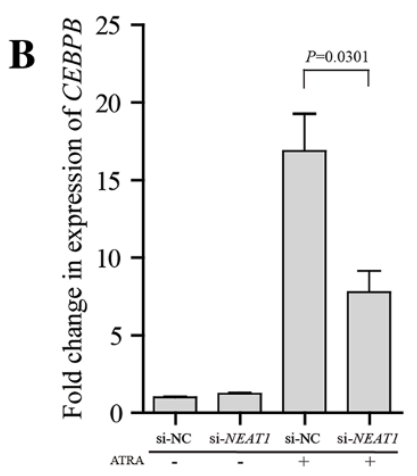

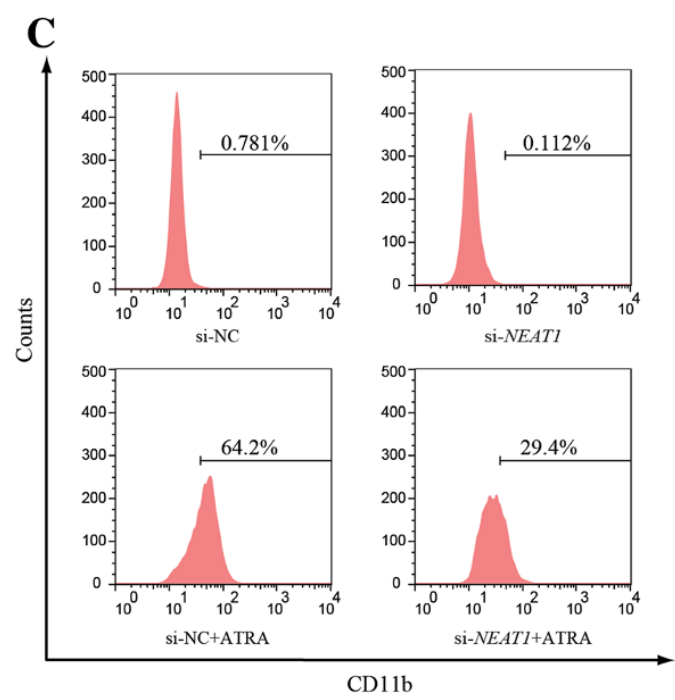

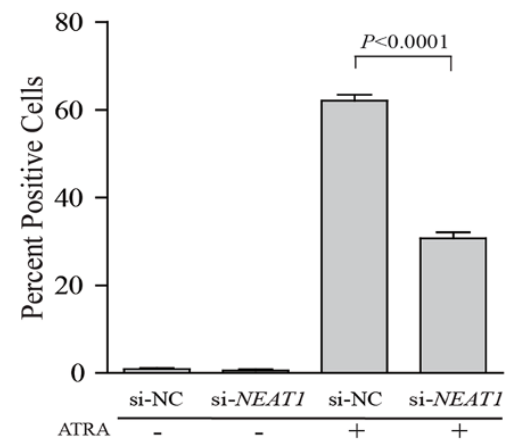

Figure 3 Knocking down NEAT1 impairs neutrophil differentiation in APL cells. (A) 48 hrs after transfection, the knockdown efficiency was confirmed by qRT-PCR. (B) CEBPB mRNA levels were measured by qRT-PCR and are given as n-fold changes compared with untreated cells and normalized to the housekeeping gene ACTB. (C) Flow cytometry analysis of ITGAM/CD11b surface expression of control and si-NEAT1 cells upon $48 \mathrm{~h}$ of ATRA-treatment $(1 \mu \mathrm{M})$. CD11 b expression was measured by flow cytometry and values were normalized to untreated control cells. Data are shown as the mean \pm SD of three separate experiments.

PML-RAR $\alpha$. Unlike ATRA, arsenic trioxide induces limited transcriptional changes of NEAT1 in APL cells (Additional file 3: Figure S3A). This result may due to arsenic trioxide induces significant cell death but only very limited differentiation $[26,27]$, and upregulation of NEAT1 in ATRA-treated APL cells is a consequence of the relief of PML-RAR $\alpha$-mediated transcriptional repression. Notably, previous studies have indicated PMLRAR $\alpha$ is able to interact with many other transcription factors, such as PU.1, providing the potential for the oncoprotein to target genes primarily regulated by other transcription factors $[7,28]$. However, due to the structural and functional complexity of PML-RAR $\alpha$, whether this regulation is by direct DNA binding or by other transcription factors requires further investigation. More importantly, this lncRNA is involved in the differentiation of APL cells, suggesting an interesting characteristic for the PML-RAR $\alpha$ oncogenic protein in the regulation of gene expression by NEAT1. The mammalian nucleus is highly organized and contains several membraneless subcompartment nuclear bodies, including nucleoli, paraspeckles, PML bodies and speckles, which are thought to be involved in gene regulation [29]. NEAT1 is a critical component of the paraspeckle structure, and paraspeckles have been proposed to be involved in the regulation of gene expression through the control of the nuclear retention of mRNAs containing long inverted repeats, which are capable of forming intramolecular double-stranded RNAs subject to adenosine-to-inosine editing [17]. More recently, NEAT1 was also shown to be involved in transcriptional regulation by sequestrating a transcriptional regulator [21]. Previous studies have demonstrated that PML-RAR $\alpha$ was capable of promoting leukemic transformation by impairing the formation of functional PML nuclear bodies [30]. Thus, PML-RAR $\alpha$ may influence the nuclear retention of structured mRNAs or gene transcription, which is indispensable for myeloid differentiation, through NEAT1. This finding is the first evidence that a 
IncRNA cooperates with a fusion protein and plays a critical role in the response to treatment. However, the underlying molecular mechanisms of NEAT1 and potential roles of paraspeckles in APL require further investigation.

In conclusion, we report abnormally decreased expression of the nuclear long noncoding RNA NEAT1, which is responsible for the differentiation block in blast cells in APL. These findings provide a more comprehensive understanding of APL pathogenesis. Because NEAT1 plays an important role in the posttranscriptional and transcriptional regulation of gene expression and we found that the expression of this nuclear long noncoding RNA was regulated by PML-RAR $\alpha$, it remains an interesting open question whether subsets of genes essential for myeloid differentiation are also modulated by perturbation of NEAT1 expression.

\section{Conclusions}

Taken together, these results are the first to assign a biological function to the nuclear long noncoding RNA NEAT1 in the myeloid differentiation of APL cells and may lead to a fuller understanding of the molecular events leading to APL.

\section{Additional files}

Additional file 1: Figure S1. Analysis of Malat1 expression in APL primary patient samples. (A) qRT-PCR and western blot analysis of Malat1 expression in granulocytes from healthy donors (Granulo, $n=12$ ) compared with primary APL cells $(n=31)$. Measured cycle threshold $(C t)$ values represent log2 expression values. The values were normalized to the expression level of the housekeeping gene ACTB. Each data point represents 1 patient sample.

Additional file 2: Figure S2. NEAT1 is suppressed by PML-RARa. (A) qRT-PCR and western blot analysis of PML-RARa in U937-PR9 cells induced with $100 \mu \mathrm{M} \mathrm{ZnSO}_{4}$. (B) qRT-PCR analysis of NEAT1 in U937 cells treated with $100 \mu \mathrm{M} \mathrm{ZnSO}_{4}$ at the indicated time points. NEAT1 was normalized to the housekeeping gene ACTB. The panels show the mean \pm SD of a representative experiment performed in triplicate. (C) GRT-PCR analysis and western blots were performed to detect PML-RARa in NB4 cells after transfection with si-PML-RARa (Student's t test was used to calculate the $p$ value).

Additional file 3: Figure S3. Analysis of NEAT1 expression. (A) qRT-PCR analysis of NEAT1 in NB4 cells treated with $2 \mu \mathrm{M}$ arsenic trioxide at the indicated time points. The ACTB level is shown as a loading control.

\section{Competing interests}

The authors declare that they have no competing interests.

\section{Authors' contributions}

CWZ designed and performed the research, analyzed data and wrote the manuscript. YX, LX, XBY, JJC, LY and SHC performed the research and analyzed data. YQL designed the research and helped draft the manuscript. All authors read and approved the final manuscript.

\section{Acknowledgments}

This study was supported by the National Natural Science Foundation of China (No. 81400102) and Guangdong Science \& Technology Project (No. 2012B050600023)
Received: 14 June 2014 Accepted: 19 September 2014

Published: 23 September 2014

\section{References}

1. de The H, Lavau C, Marchio A, Chomienne C, Degos L, Dejean A: The PML-RAR alpha fusion mRNA generated by the $t(15 ; 17)$ translocation in acute promyelocytic leukemia encodes a functionally altered RAR. Cell 1991, 66(4):675-684.

2. Huang ME, Ye YC, Chen SR, Chai JR, Lu JX, Zhoa L, Gu LJ, Wang ZY: Use of all-trans retinoic acid in the treatment of acute promyelocytic leukemia. Blood 1988, 72(2):567-572.

3. Breitman TR, Collins SJ, Keene BR: Terminal differentiation of human promyelocytic leukemic cells in primary culture in response to retinoic acid. Blood 1981, 57(6):1000-1004

4. Nasr R, Guillemin MC, Ferhi O, Soilihi H, Peres L, Berthier C, Rousselot $P$, Robledo-Sarmiento M, Lallemand-Breitenbach V, Gourmel B, Vitoux D, Pandolfi PP, Rochette-Egly C, Zhu J, and de The H: Eradication of acute promyelocytic leukemia-initiating cells through PML-RARA degradation. Nat Med 2008, 14(12):1333-1342.

5. Zhu J, Gianni M, Kopf E, Honore N, Chelbi-Alix M, Koken M, Quignon F, Rochette-Egly C, de The H: Retinoic acid induces proteasome-dependent degradation of retinoic acid receptor alpha (RARalpha) and oncogenic RARalpha fusion proteins. Proc Natl Acad Sci U S A 1999, 96(26):14807-14812

6. Isakson P, Bjoras M, Boe SO, Simonsen A: Autophagy contributes to therapy-induced degradation of the PML/RARA oncoprotein. Blood 2010, 116(13):2324-2331

7. Wang K, Wang P, Shi J, Zhu X, He M, Jia X, Yang X, Qiu F, Jin W, Qian M, Fang H, Mi J, Yang X, Xiao H, Minden M, Du Y, Chen Z, Zhang J: PML/ RARalpha targets promoter regions containing PU.1 consensus and RARE half sites in acute promyelocytic leukemia. Cancer Cell 2010, 17(2):186-197.

8. Ablain J, de The H: Revisiting the differentiation paradigm in acute promyelocytic leukemia. Blood 2011, 117(22):5795-5802.

9. Payton JE, Grieselhuber NR, Chang LW, Murakami M, Geiss GK, Link DC, Nagarajan R, Watson MA, Ley TJ: High throughput digital quantification of mRNA abundance in primary human acute myeloid leukemia samples. J Clin Invest 2009, 119(6):1714-1726.

10. Viale A, De Franco F, Orleth A, Cambiaghi V, Giuliani V, Bossi D, Ronchini C, Ronzoni S, Muradore I, Monestiroli S, Gobbi A, Alcalay M, Minucci S, Pelicci PG: Cell-cycle restriction limits DNA damage and maintains self-renewal of leukaemia stem cells. Nature 2009, 457(7225):51-56

11. Sun $Y M$, Lin $K Y$, Chen $Y Q$ : Diverse functions of miR-125 family in different cell contexts. J Hematol Oncol 2013, 6:6.

12. Zeng $C W$, Zhang $X J$, Lin KY, Ye H, Feng SY, Zhang $H$, Chen $Y Q$ : Camptothecin induces apoptosis in cancer cells via microRNA-125bmediated mitochondrial pathways. Mol Pharmacol 2012, 81(4):578-586.

13. Zhang $H$, Chen Z, Wang $X$, Huang Z, He Z, Chen Y: Long non-coding RNA: a new player in cancer. J Hematol Onco 2013, 6:37.

14. Zhuang $Y$, Wang $X$, Nguyen $H T$, Zhuo $Y$, Cui $X$, Fewell C, Flemington EK, Shan B: Induction of long intergenic non-coding RNA HOTAIR in lung cancer cells by type I collagen. J Hematol Oncol 2013, 6:35.

15. Sunwoo H, Dinger ME, Wilusz JE, Amaral PP, Mattick JS, Spector DL: MEN epsilon/beta nuclear-retained non-coding RNAs are up-regulated upon muscle differentiation and are essential components of paraspeckles. Genome Res 2009, 19(3):347-359.

16. Naganuma T, Hirose T: Paraspeckle formation during the biogenesis of long non-coding RNAs. RNA Biol 2013, 10(3):456-461.

17. Chen $L L$, Carmichael GG: Altered nuclear retention of mRNAs containing inverted repeats in human embryonic stem cells: functional role of a nuclear noncoding RNA. Mol Cell 2009, 35(4):467-478.

18. Grignani F, Ferrucci PF, Testa U, Talamo G, Fagioli M, Alcalay M, Mencarelli A, Grignani F, Peschle C, Nicoletti I, Pelicci PG: The acute promyelocytic leukemia-specific PML-RAR alpha fusion protein inhibits differentiation and promotes survival of myeloid precursor cells. Cell 1993, 74(3):423-431.

19. Miyake M, Hayashi S, Iwasaki S, Chao G, Takahashi H, Watanabe K, Ohwada $\mathrm{S}$, Aso H, Yamaguchi T: Possible role of TIEG1 as a feedback regulator of myostatin and TGF-beta in myoblasts. Biochem Biophys Res Commun 2010, 393(4):762-766.

20. Ward SV, Sternsdorf T, Woods NB: Targeting expression of the leukemogenic PML-RARalpha fusion protein by lentiviral vectormediated small interfering RNA results in leukemic cell differentiation and apoptosis. Hum Gene Ther 2010, 22(12):1593-1598. 
21. Imamura K, Imamachi N, Akizuki G, Kumakura M, Kawaguchi A, Nagata K, Kato A, Kawaguchi Y, Sato H, Yoneda M, Kai C, Yada T, Suzuki Y, Yamada T, Ozawa T, Kaneki K, Inoue T, Kobayashi M, Kodama T, Wada Y, Sekimizu K, Akimitsu N: Long noncoding RNA NEAT1-dependent SFPQ relocation from promoter region to paraspeckle mediates IL8 expression upon immune stimuli. Mol Cell 2014, 53(3):393-406.

22. Zhang $Q$, Chen $C Y$, Yedavalli VS, Jeang KT: NEAT1 long noncoding RNA and paraspeckle bodies modulate HIV-1 posttranscriptional expression. MBio 2013, 4(1):e00596-00512.

23. Sasaki YT, Ideue T, Sano M, Mituyama T, Hirose T: MENepsilon/beta noncoding RNAs are essential for structural integrity of nuclear paraspeckles. Proc Natl Acad Sci U S A 2009, 106(8):2525-2530.

24. Duprez E, Wagner $\mathrm{K}$, Koch $\mathrm{H}$, Tenen DG: C/EBPbeta: a major PML-RARAresponsive gene in retinoic acid-induced differentiation of APL cells. EMBO J 2003, 22(21):5806-5816.

25. Schlafli AM, Torbett BE, Fey MF, Tschan MP: BIRC6 (APOLLON) is downregulated in acute myeloid leukemia and its knockdown attenuates neutrophil differentiation. Exp Hematol Oncol 2012, 1(1):25.

26. Rogers CS, Yedjou CG, Sutton DJ, Tchounwou PB: Vitamin D3 potentiates the antitumorigenic effects of arsenic trioxide in human leukemia (HL-60) cells. Exp Hematol Oncol 2014, 3(1):9.

27. Chen GQ, Zhu J, Shi XG, Ni JH, Zhong HJ, Si GY, Jin XL, Tang W, Li XS, Xong SM, Shen ZX, Sun GL, Ma J, Zhang P, Zhang TD, Gazin C, Naoe T, Chen SJ, Wang ZY, Chen Z: In vitro studies on cellular and molecular mechanisms of arsenic trioxide (As2O3) in the treatment of acute promyelocytic leukemia: As2O3 induces NB4 cell apoptosis with downregulation of BCl-2 expression and modulation of PML-RAR alpha/PML proteins. Blood 1996, 88(3):1052-1061.

28. Qian $M$, Jin W, Zhu X, Jia X, Yang X, Du Y, Wang K, Zhang J: Structurally differentiated cis-elements that interact with PU.1 are functionally distinguishable in acute promyelocytic leukemia. J Hematol Oncol 2013, 6:25.

29. Spector DL: SnapShot: cellular bodies. Cell 2006, 127(5):1071.

30. Zhong S, Hu P, Ye TZ, Stan R, Ellis NA, Pandolfi PP: A role for PML and the nuclear body in genomic stability. Oncogene 1999, 18(56):7941-7947.

\section{Submit your next manuscript to BioMed Central and take full advantage of:}

- Convenient online submission

- Thorough peer review

- No space constraints or color figure charges

- Immediate publication on acceptance

- Inclusion in PubMed, CAS, Scopus and Google Scholar

- Research which is freely available for redistribution 